\title{
The ascending limb of the cocaine dose-response curve for reinforcing effect in rhesus monkeys
}

Received: 16 July 2002 / Accepted: 31 October 2002 / Published online: 16 January 2003

(C) Springer-Verlag 2003

\begin{abstract}
Rationale: To date, the literature on the intravenous self-administration of cocaine by laboratory animals lacks a compelling demonstration of an ascending limb to the dose-response function. It has been argued that previous demonstrations of an ascending limb are confounded by the extinction process. Objective: The objective was to examine the relationship between cocaine dose and intravenous self-injection frequency at the low end of the cocaine dose range $(0.03-0.00075 \mathrm{mg} /$ kg per injection). Methods: Three adult rhesus monkeys were given the opportunity to self-inject cocaine on a fixed-ratio 1 schedule of reinforcement with no timeouts between injections. Single cocaine doses were presented for between 13 and 27 consecutive 2-h sessions in the order of $0.03,0.01,0.003,0.0015_{a}, 0.00075$, and $0.0015_{b}$ $\mathrm{mg} / \mathrm{kg}$ per injection. Results: An ascending limb of the cocaine dose-response curve was found to exist between the doses of 0.00075 and $0.003 \mathrm{mg} / \mathrm{kg}$ per injection. Conclusions: The fact that response rate increased from 0.00075 to $0.0015_{\mathrm{b}} \mathrm{mg} / \mathrm{kg}$ per injection, and remained stable at this intermediate level, negates the possibility that responding at $0.0015_{\mathrm{b}} \mathrm{mg} / \mathrm{kg}$ per injection is an artifact of experimental extinction. The finding that significantly less cocaine was taken at $0.0015_{\mathrm{b}} \mathrm{mg} / \mathrm{kg}$ per injection than at higher doses demonstrates that satiety was not the mechanism by which cocaine intake was regulated on the ascending limb of the dose-response curve.
\end{abstract}

\footnotetext{
G. S. Flory · J. H. Woods $(\bowtie)$

Department of Psychology,

University of Michigan,

Ann Arbor, MI 48109, USA

e-mail: jhwoods@umich.edu

Tel.: +1-734-7649133

Fax: +1-734-7647118

J. H. Woods

Department of Pharmacology,

University of Michigan,

Ann Arbor, MI 48109, USA
}

Keywords Cocaine · Intravenous · FR1 $\cdot$ Rhesus monkey · Reinforcement

\section{Introduction}

Two models of the regulation of intravenous cocaine selfadministration have recently been put forth (Tsibulsky and Norman 1999; Sizemore and Martin 2000). Central to both of these models is the assumption that cocaine selfadministration is an all-or-none phenomenon, being either present or absent. Sizemore and Martin (2000) have devised a mathematical theory of drug self-administration in which steady states of responding only occur either at a maximum rate or not at all. They contend that intermediate rates of responding, which comprise the ascending limb of the dose-response curve, will be driven to either one of these extremes. Indeed, this model describes findings of the rodent intravenous cocaine self-administration literature.

Moving beyond the descriptive, Norman and Tsibulsky (1999) attempt to explain the quantal nature of responding for intravenous cocaine injections by rats in terms of the attainment of a state of satiety. That is, rats selfadminister cocaine in order to prevent circulating cocaine levels from falling below a minimum level at which the animals are satiated. When the cocaine dose per injection is manipulated by the experimenter, the rate at which the animals respond will either increase or decrease in order to maintain the same constant level of circulating cocaine. If access to the drug is constrained by the imposition of large response requirements or lengthy inter-injection timeout periods, responding may persist for several sessions; however, unable to achieve this constant level of circulating cocaine, the animals will eventually stop responding. The ascending limb of the dose-response function is therefore viewed as an artifact brought about by averaging rates of responding, when obtained, across sessions during which the animals gradually stop responding. Thus, it is argued that when timeout periods are not used, and an injection is made available following 
each response (fixed ratio 1), the ascending limb of the cocaine dose-response function diminishes and disappears (Norman and Tsibulsky 2001).

There are few published reports in which rats were given the opportunity to intravenously self-administer cocaine on a fixed ratio 1 schedule of reinforcement with no timeout periods imposed between injections. The earliest study, conducted by Pickens and Thompson (1968), found an inverse relationship to exist between cocaine dose and rate of responding. Response rate was found to decrease as cocaine dose increased from 0.5 to $2.5 \mathrm{mg} / \mathrm{kg}$ per injection. In this study, responding was not maintained at a dose of $0.25 \mathrm{mg} / \mathrm{kg}$ per injection. However, the possibility that an ascending limb of the dose-response function might exist between the two lowest doses was not examined.

Shortly after the initial report by Pickens and Thompson (1968), Wilson and colleagues (1971) conducted a similar series of experiments using rhesus monkeys. In this latter study, an ascending limb of the cocaine doseresponse curve was found at doses of between 0.025 and $0.05 \mathrm{mg} / \mathrm{kg}$ per injection. However, the drug injection apparatus used in this study required approximately $25 \mathrm{~s}$ to reload after each injection (for a detailed description of the apparatus, see Deneau et al. 1969). Thus, a timeout period of $25 \mathrm{~s}$ inevitably followed each injection, which itself was delivered over the course of $25 \mathrm{~s}$. In addition, the authors note that at these two lowest doses, the injection apparatus was "almost constantly operating throughout the session" (Wilson et al. 1971). The number of injections that the animals could receive under these conditions was therefore limited. Moreover, individual session data were not presented, and so, it is impossible to assess whether or not response rates on the ascending limb of the dose-response function were stable. The present study therefore sought to repeat the earlier work of Wilson and colleagues (1971) using a considerably more rapid 5-s injection time with no timeouts between injections. To ensure that response rate on the ascending limb of the dose-response function was not in transition to experimental extinction, for purpose of comparison, the second lowest dose was presented after both a higher and a lower dose.

\section{Materials and methods}

\section{Subjects}

Three adult rhesus monkeys (Macaca mulatta; two males and one female), weighing between 8.1 and $13.7 \mathrm{~kg}$ served as subjects. All animals were naive to cocaine, although each had approximately 4 months of prior exposure to both oral and intravenous ethanol. Each monkey was individually housed in a stainless steel cage measuring $83.8 \mathrm{~cm}$ highx76.2 cm widex91.4 cm deep (Bryan Research Equipment Corporation, Bryan, Tex., USA). The animals' daily diet consisted of approximately 30 Purina Monkey Chow biscuits (7 g: Ralston-Purina, St Louis, Mo., USA) and water. The diet was supplemented three times per week with fresh fruit and vegetables. The laboratory was illuminated from 6:30 a.m. to 8:30 p.m.
Each monkey had an indwelling venous catheter in either the right or left femoral vein. Catheters were inserted during aseptic surgery under ketamine $(10 \mathrm{mg} / \mathrm{kg})$ and xylazine $(2 \mathrm{mg} / \mathrm{kg})$ anesthesia. The catheter was tunneled subcutaneously to the midscapular region, where it exited the animal's body and connected to a peristaltic infusion pump (Cole-Parmer, Vernon Hills, Ill., USA) located on a shelf behind the animal's cage. The external portion of the catheter was protected inside the cage by a flexible steel tube. One end of the tube was attached to a polyester fabric jacket (Lomir Biomedical, New York, N.Y., USA) worn by the animals and the other end was bolted to the rear of the cage. Experimental protocols were approved by the University of Michigan's Office of the University Committee on Use and Care of Animals and were conducted in accordance with the "Guidelines of the Committee on the Care and Use of Laboratory Animal Resources" (National Health Council, Department of Health, Education and Welfare, ISBN 0-309-05377-3, revised 1996).

\section{Self-administration procedure}

To the side wall of each cage was mounted a $15 \mathrm{~cm}$ wide by $20 \mathrm{~cm}$ high panel, from which two response levers protruded $2.5 \mathrm{~cm}$ into the cage. A force of approximately $0.36 \mathrm{~N}$ was required to depress a lever and signal a response to an IBM compatible computer interfaced with Med-Associates hardware and software (MedAssociates, Georgia, Vt., USA). A stimulus light located $8 \mathrm{~cm}$ above each lever was illuminated green to signal drug availability. Each response on the active lever (fixed ratio 1) resulted in the injection of $1 \mathrm{ml}$ of a cocaine solution infused over the course of $5 \mathrm{~s}$. During an infusion, the green stimulus light was extinguished and an orange light was flashed on and off once each second. Immediately after an infusion, the green stimulus light above the lever was again illuminated to signal the availability of a subsequent injection.

Self-administration sessions were held between 7 a.m. and 9 a.m. and 4 p.m. and 6 p.m., 7 days per week. Lever pressing behavior was shaped by reinforcing successive approximations of the response with investigator-initiated injections of $0.03 \mathrm{mg} / \mathrm{kg}$ per injection cocaine. All animals were successfully trained to respond on a fixed ratio 1 schedule of reinforcement for the $0.03 \mathrm{mg} / \mathrm{kg}$ per injection dose within approximately $20 \mathrm{~min}$.

The concentrations of the cocaine solutions were adjusted based on an individual subject's body weight. The doses tested were 0.03 , $0.01,0.003,0.0015$, and $0.00075 \mathrm{mg} / \mathrm{kg}$ per injection. The doses were presented in descending order, with the $0.0015 \mathrm{mg} / \mathrm{kg}$ per injection dose being replicated after the $0.00075 \mathrm{mg} / \mathrm{kg}$ per injection dose. Thus, the order in which the different doses were presented to the animals was $0.03,0.01,0.003,0.0015_{\mathrm{a}}, 0.00075$, and $0.0015_{\mathrm{b}}$. To avoid toxicity, total session cocaine intake was limited to a maximum of $1.5 \mathrm{mg} / \mathrm{kg}$. Within the context of between 13 and 27 consecutive sessions, a given dose was changed only after a minimum of five consecutive sessions during which there was neither an increasing nor decreasing trend in total session response rate.

\section{Data analysis}

To assess the presence or absence of an increasing or decreasing trend in response rate across five consecutive sessions during which a single dose was available, a linear regression was performed using the least squares method. Response rate was deemed stable if the slope of the regression line was not significantly different from $0(P>0.05)$. To determine whether or not there was a stable ascending limb of the dose-response function, a one-way ANOVA was first performed on the average number of responses per session made during the last five sessions at doses of $0.003,0.0015_{\mathrm{a}}$, 0.00075 , and $0.0015_{\mathrm{b}} \mathrm{mg} / \mathrm{kg}$ per injection. If a significant $F$ ratio was found, pairwise comparisons were then made between the average number of responses per session during the last five sessions at these doses using a two-sample $t$-test. 
Fig. 1 For each of the three monkeys (M1, M2, and M3), total session cocaine intake $(\mathrm{mg} / \mathrm{kg}$ per $2 \mathrm{~h})$ is plotted in the left column of graphs and the corresponding rate of responding (responses/s) is plotted in the right column of graphs. The data are presented in the order in which they were collected over the course of approximately 100 consecutive, twicedaily test sessions

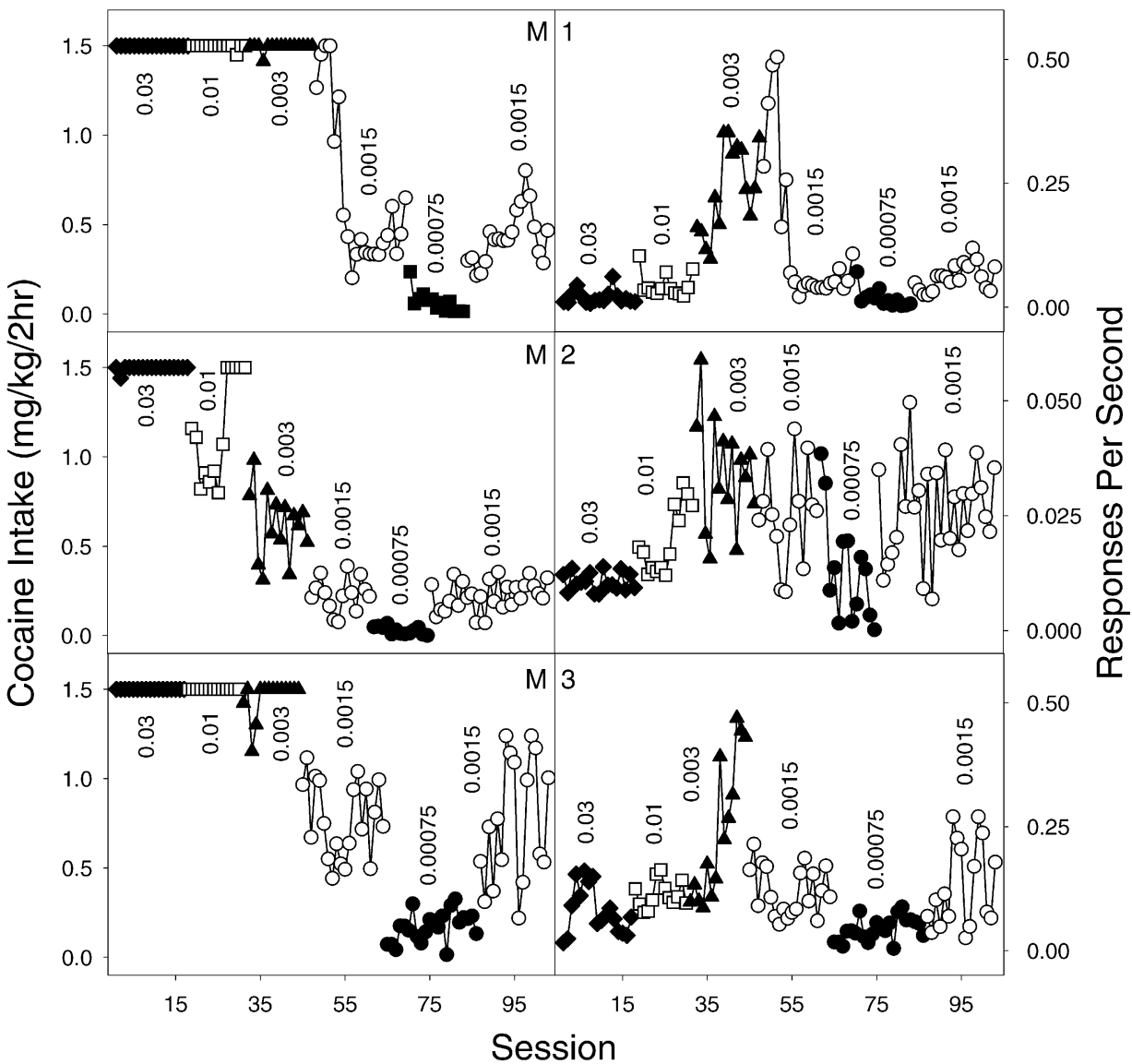

Table 1 Average rate of responding $( \pm$ SEM) is presented for the last five sessions at each cocaine dose tested. The slope of the regression line fit to response rate during these last five sessions is

\begin{tabular}{|c|c|c|c|c|c|c|}
\hline Dose (mg/kg per injection) & 0.03 & 0.01 & 0.003 & $0.0015_{\mathrm{a}}$ & 0.00075 & $0.0015 \mathrm{~b}$ \\
\hline \multicolumn{7}{|l|}{ Monkey 1} \\
\hline $\begin{array}{l}\text { Response/s } \\
\text { SEM } \\
\text { Slope } \\
\text { Significance }\end{array}$ & $\begin{array}{l}0.015 \\
0.002 \\
\mathrm{~b}=-0.0025 \\
P=0.11\end{array}$ & $\begin{array}{l}0.039 \\
0.01 \\
\mathrm{~b}=0.011 \\
P=0.12\end{array}$ & $\begin{array}{l}0.26 \\
0.03 \\
\mathrm{~b}=0.0050 \\
P=0.84\end{array}$ & $\begin{array}{l}0.065 \\
0.01 \\
\mathrm{~b}=0.0087 \\
P=0.39\end{array}$ & $\begin{array}{l}0.0061 \\
0.002 \\
\mathrm{~b}=-0.00039 \\
P=0.83\end{array}$ & $\begin{array}{l}0.062 \\
0.01 \\
\mathrm{~b}=-0.0059 \\
P=0.58\end{array}$ \\
\hline \multicolumn{7}{|l|}{ Monkey 2} \\
\hline $\begin{array}{l}\text { Response/s } \\
\text { SEM } \\
\text { Slope } \\
\text { Significance }\end{array}$ & $\begin{array}{l}0.011 \\
0.001 \\
\mathrm{~b}=-0.000094 \\
P=0.91\end{array}$ & $\begin{array}{l}0.028 \\
0.001 \\
\mathrm{~b}=0.00053 \\
P=0.66\end{array}$ & $\begin{array}{l}0.031 \\
0.004 \\
\mathrm{~b}=0.0021 \\
P=0.51\end{array}$ & $\begin{array}{l}0.027 \\
0.005 \\
\mathrm{~b}=0.00097 \\
P=0.79\end{array}$ & $\begin{array}{l}0.0077 \\
0.003 \\
\mathrm{~b}=-0.0024 \\
P=0.33\end{array}$ & $\begin{array}{l}0.030 \\
0.004 \\
\mathrm{~b}=-0.0016 \\
P=0.56\end{array}$ \\
\hline \multicolumn{7}{|l|}{ Monkey 3} \\
\hline $\begin{array}{l}\text { Response/s } \\
\text { SEM } \\
\text { Slope } \\
\text { Significance }\end{array}$ & $\begin{array}{l}0.047 \\
0.009 \\
\mathrm{~b}=-0.000085 \\
P=0.99\end{array}$ & $\begin{array}{l}0.11 \\
0.009 \\
\mathrm{~b}=0.0024 \\
P=0.75\end{array}$ & $\begin{array}{l}0.39 \\
0.04 \\
\mathrm{~b}=0.046 \\
P=0.095\end{array}$ & $\begin{array}{l}0.12 \\
0.02 \\
\mathrm{~b}=0.0018 \\
P=0.91\end{array}$ & $\begin{array}{l}0.053 \\
0.007 \\
\mathrm{~b}=-0.0070 \\
P=0.081\end{array}$ & $\begin{array}{l}0.17 \\
0.04 \\
\mathrm{~b}=-0.035 \\
P=0.28\end{array}$ \\
\hline
\end{tabular}

presented along with the test of the slope's difference from zero (to assess stability of responding)

\section{Results}

Response rate and total session cocaine intake is presented for all sessions in Figure 1. To quantify stability of responding during the last five sessions at each dose tested, a linear regression was performed and it was determined whether or not the slope of the regression line 
0.00075 , and $0.0015_{\mathrm{b}} \mathrm{mg} / \mathrm{kg}$ per injection revealed a significant difference among the means for each monkey: monkey 1, $F(3,16)=45.4 \quad\left(P=4.7 \times 10^{-8}\right) ;$ monkey 2, $F(3,16)=9.36 \quad(P=0.0008) ; \quad$ monkey $3, \quad F(3,16)=22.3$ $\left(P=5.8 \times 10^{-6}\right)$. For all monkeys, a two-tail $t$-test revealed no significant difference in response rate between the two determinations of the $0.0015 \mathrm{mg} / \mathrm{kg}$ per injection dose. In addition, a one-tail t-test revealed that, for each monkey, the difference in response rate between the $0.0015_{\mathrm{a}} \mathrm{mg} / \mathrm{kg}$ per injection dose and the $0.00075 \mathrm{mg} / \mathrm{kg}$ per injection dose was significant: monkey $1, t(4)=5.17 \quad(P=0.003)$; monkey 2, $t(4)=3.50 \quad(P=0.012)$; monkey $3, t(4)=3.47$ $(P=0.013)$. Only for monkeys 1 and 3 was the difference in response rate between the $0.0015_{\mathrm{a}}$ and $0.003 \mathrm{mg} / \mathrm{kg}$ per injection doses significant: monkey $1, t(4)=8.89$ $(P=0.0004)$; monkey $2, t(4)=0.62(P=0.28)$; monkey 3 , $\mathrm{t}(4)=6.41(P=0.001)$.

Response rate for monkey 2 was considerably more variable at the lower doses than it was for the other two monkeys. Given this increased variability, for monkey 2 , response rate for the last ten sessions of each dose was analyzed rather than the last five. A post-hoc trend analysis (conducted as described above) revealed that response rates for the last ten sessions at the doses of $0.003,0.0015_{\mathrm{a}}, 0.00075$, and $0.0015_{\mathrm{b}} \mathrm{mg} / \mathrm{kg}$ per injection were stable: $-0.00093 \quad(P=0.34), 0.0018 \quad(P=0.19)$, $-0.00088 \quad(P=0.32), 0.00059 \quad(P=0.45)$. A one-way ANOVA revealed a significant difference to exist among the mean response rates at these doses: $F(3,36)=14.02$ $\left(P=3.3 \times 10^{-6}\right)$. A two-tail $t$-test revealed no significant difference between response rate over the last ten sessions at the two determinations of the $0.0015 \mathrm{mg} / \mathrm{kg}$ per injection dose. Using a one-tail $t$-test, a significant difference between response rates at the $0.0015_{\mathrm{a}}$ and $0.00075 \mathrm{mg} / \mathrm{kg}$ per injection doses was found: $t(9)=2.83$ $(P=0.0098)$. Finally, at the 0.003 and $0.0015_{\mathrm{a}} \mathrm{mg} / \mathrm{kg}$ per injection doses, a significant difference in response rates was found using a one-tail $t$-test: $t(9)=2.13(P=0.03)$.

\section{Discussion}

The data presented in this report reveal that an ascending limb of the cocaine dose-response function exists (albeit an extremely steep one). Response rate was greater at $0.0015 \mathrm{mg} / \mathrm{kg}$ per injection than at $0.00075 \mathrm{mg} / \mathrm{kg}$ per injection. In addition, response rate at $0.003 \mathrm{mg} / \mathrm{kg}$ per injection was greater than at $0.0015 \mathrm{mg} / \mathrm{kg}$ per injection. The significance of these results is that, on the ascending limb of the dose-response function, the amount of cocaine consumed is significantly less than it is at higher doses. This clearly indicates that satiety cannot be the mechanism by which drug intake is regulated at these lowest doses. In spite of previous demonstrations that lower cocaine doses engender lower levels of intake, it has been argued that this phenomenon is an artifact of a transition to experimental extinction (Norman and Tsibulsky 2001). That is, unable to maintain a constant level of circulating cocaine at a fixed "satiety threshold" (Tsibulsky and Norman 1999), an animal will eventually stop responding for the drug. However, the fact that response rate was found to increase from 0.00075 to $0.0015_{\mathrm{b}} \mathrm{mg} / \mathrm{kg}$ per injection negates the possibility that responding at $0.0015 \mathrm{~b} \mathrm{mg} / \mathrm{kg}$ per injection was in the process of decreasing, as in experimental extinction.

Previous studies have shown that stable patterns of responding can be maintained in non-human primates by relatively few injections of cocaine on progressive-ratio (Griffiths et al. 1978) and second-order (Goldberg et al. 1975) schedules of reinforcement. In addition, rats have been found to respond robustly on second-order schedules of cocaine reinforcement in which only a limited number of injections are given (for review, see Everitt and Robbins 2000). These results further demonstrate that, for both rats and non-human primates, the attainment of a cumulative level of cocaine intake is not required in order to maintain self-administration behavior.

Acknowledgements This work was supported by USPHS grants DA-09161 and 1 F31 AA13224-01.

\section{References}

Deneau G, Yanagita T, Seevers MH (1969) Self-administration of psychoactive substances by the monkey. Psychopharmacologia 16:30-48

Everitt BJ, Robbins TW (2000) Second-order schedules of drug reinforcement in rats and monkeys: measurement of reinforcing efficacy and drug-seeking behaviour. Psychopharmacology 153:17-30

Goldberg SR, Kelleher RT, Morse WH (1975) Second-order schedules of drug injection. Fed Proc 34:1771-1176

Griffiths RR, Brady JV, Snell JD (1978) Progressive-ratio performance maintained by drug infusions: comparison of cocaine, diethylpropion, chlorphentermine, and fenfluramine. Psychopharmacology 56:5-13

Norman AB, Tsibulsky VL (2001) Satiety threshold regulates maintained self-administration: comment on Lynch and Carroll (2001). Exp Clin Psychopharmacol 9:151-154; discussion 160 162

Pickens R, Thompson T (1968) Cocaine-reinforced behavior in rats: effects of reinforcement magnitude and fixed-ratio size. $\mathrm{J}$ Pharmacol Exp Ther 161:122-129

Sizemore GM, Martin TJ (2000) Toward a mathematical description of dose-effect functions for self-administered drugs in laboratory animal models. Psychopharmacology 153:57-66

Tsibulsky VL, Norman AB (1999) Satiety threshold: a quantitative model of maintained cocaine self-administration. Brain Res 839:85-93

Wilson MC, Hitomi M, Schuster CR (1971) Psychomotor stimulant self administration as a function of dosage per injection in the rhesus monkey. Psychopharmacologia 22:271-281 